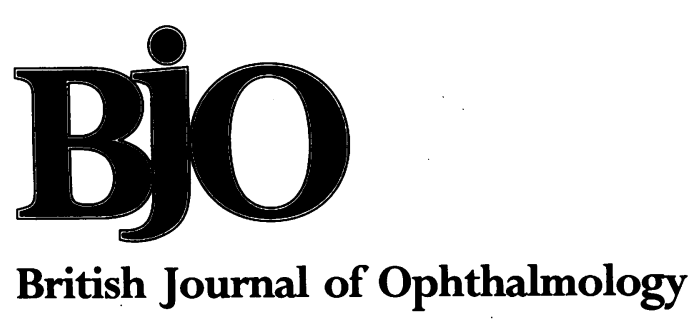

High frequency ultrasound (HFU), is a new development in the field of ophthalmic imaging. This B-scan technique operates at a sound frequency ranging between 50 and 100 $\mathrm{MHz}$, a 10-fold greater frequency than that used in conventional B-scan. At this frequency, microscopic images of tissues are obtained at a magnification approaching that of light microscopy. The pioneering work and commercial development of HFU in ophthalmology are credited to Charles J Pavlin, Michael D Sherar, and F Stuart Foster in Toronto. In 1990 they described the first instrument, ${ }^{1}$ and in 1991 published a compilation of clinical uses of this modality which they termed ultrasound biomicroscopy (UBM). ${ }^{2}$

Although new to the clinical setting, HFU has been used for many years to examine biological material in the laboratory. An 'acoustic microscope' was developed in 1974 by Lemons and Quate at Stanford University. ${ }^{3}$ The frequency of sound of this apparatus was even greater than UBM, reaching levels of up to $1000 \mathrm{MHz}$. In 1977, Lemons and co-workers used the acoustic microscope to examine human retina and pigment epithelium. ${ }^{4}$ Theirs were the first images of human eye tissue to be demonstrated by this technique. Tissues were fixed and stained for conventional light and acoustic microscopy. Other sections were prepared by the frozen section method to compare the acoustic images of fixed and non-fixed samples. The result was an impressive resemblance between light and acoustic microscopy, with the acoustic microscope displaying the 'viscoelastic' rather than the optical properties of tissues. One important finding from their study is that fixation and staining are not necessary in acoustic microscopy, therefore fresh samples can be examined and studied under normal and pathological conditions.

Further modifications were introduced by Sherar and Foster. These included the design of high frequency poly (vinylidene fluoride) (PVDF) transducers. ${ }^{56}$ PVDF were central to the progress achieved in HFU technology, because of their low mechanical impedance and broadband properties. Another modification was the use of backscatter (pulse echo) technique ${ }^{7}$; a familiar and well tested process in medical ultrasound. Initially, Sherar, Noss, and Foster used the C-scan method. ${ }^{8}$ Although images were of high quality, examination was time consuming as it took 10 minutes to scan tissues in 'two dimensions' and produce complete images. Later, Sherar and co-workers employed the B-scan method to produce images at a rate of five frames per second. ${ }^{7}$ This allowed rapid feedback to the operator, and brought this technique much closer to the clinical setting. In collaboration with Pavlin, more refinements in the field of view, and other electronic features, have also been made. ${ }^{2}$

HFU achieves high lateral and axial resolutions, ranging between 20 and $40 \mu \mathrm{m}^{1}$ which is also 10 -fold greater than conventional B-scan. However, high resolution is won against the loss of penetration. In HFU, only the first 2 to $4 \mathrm{~mm}$ of tissue are clearly imaged, compared with 20 to 40 $\mathrm{mm}$ in conventional B-scan. Fortunately, most of the anterior segment structures are within the range of HFU.

In this issue of the $B \mathcal{F O}$ (p 972), Aslanides et al used HFU to investigate mechanisms of pupillary block glaucoma. The ultrasonographic images of the anterior ocular structures are remarkably clear and show, in microscopic detail, the cornea with its individual layers, iris, ciliary body, intraocular lens, and profiles of the anterior and posterior chambers and draining angle.

Currently, three main applications of HFU can be identified: (a) corneal pachymetry and topography, (b) imaging of anterior segment lesions, and (c) investigation of various types of glaucoma.

Corneal pachymetry using HFU has proved more accurate than conventional ultrasound and optical pachymetry, particularly if the cornea is opacified. ${ }^{9-13}$ The in vivo microscopic examination of corneal layers is likely to be informative in the management of patients undergoing refractive corneal surgery, ${ }^{14}$ and in the observation of epithelial dystrophy, ${ }^{9}$ and corneal graft rejection. ${ }^{2}$

Although optical biomicroscopy remains the primary examination method of anterior segment lesions, HFU will have the advantage in circumstances such as corneal opacification, and posterior synechiae. Even in clear media, HFU will offer unique subsurface images, useful in cases such as anterior scleral lesions, ${ }^{15}$ anterior segment tumours, ${ }^{216}$ and posterior iris cysts ${ }^{16}$; the definitive diagnosis of the latter may only be possible with HFU. Of importance in this context are the findings of Memmen et al $^{17}$ and Jakobiec et al ${ }^{18}$ that $53 \%$ of series of iridocyclectomies and $87 \%$ of iridectomies, removed because of suspected malignancy, proved to contain benign lesions.

Biometry of the anterior chamber with HFU provides measurement throughout its entire length and not only axially. ${ }^{19}$ Studies have shown the value of HFU in profiling the draining angle and iris root, ${ }^{219-22}$ and in offering, especially with real time motion studies, a better understanding of the mechanisms of angle closure glaucoma. ${ }^{19}$ Aslanides et al were able to differentiate, with confidence, between pupillary block glaucoma and aqueous 
misdirection; an important distinction since each requires a different therapeutic approach. ${ }^{22-24}$

Caution is needed before undertaking HFU examination. A degree of experience in conventional B-scanning is useful to familiarise the operator with the acquisition of images and interpretation of results. Also, HFU will not replace conventional ultrasound, as large lesions in the anterior segment and those in the posterior segment are too deep to be scanned. The sound velocities in ocular tissues, although known with accuracy at the conventional range, are not yet established at higher frequencies. Biometry results therefore should be interpreted with caution using HFU.

Some practical aspects should also be considered. The transducers of HFU are not covered by a membrane, ${ }^{2}$ hence the need to conduct examination through a waterbath to prevent corneal abrasion. The safety of the technique has also to be considered. The latest guidelines suggest that spatial peak temporal average power levels (SPTA) must not exceed $100 \mathrm{~mW} / \mathrm{cm}^{2}$ and UBM produces SPTA intensity of $22 \mathrm{~mW} / \mathrm{cm}^{2}$ which is considerable. ${ }^{2}$

There is little doubt, however, that HFU will become an essential addition to conventional ultrasound scanning, and as the technique is further refined, newer applications will be discovered. The article by Aslanides et al is an example of such applications and the images illustrated are a yardstick for future studies.

HATEM R ATTA

Eye Department,

Aberdeen Royal Infirmary,

Foresterhill, Aberdeen AB9 2ZB

1 Pavlin CJ, Sherar MD, Foster FS. Subsurface ultrasound microscopic imaging of the intact eye. Ophthalmology 1990; 97: 244-50.

2 Pavlin CJ, Harasiewicz K, Sherar MD, Foster FS. Clinical use of ultrasound biomicroscopy. Ophthalmology 1991; 98: 287-95.

3 Lemons RA, Quate CF. Acoustic microscopy with mechanical scanning. Appl Phys Lett 1974; 24: 163-5.
4 Marmor MF, Wickramasinghe HK, Lemons RA. Acoustic microscopy of the human retina and pigment epithelium. Invest Ophthalmol Vis Sci 1977; 16: $660-6$.

5 Sherar MD, Foster FS. A $100 \mathrm{MHz}$ PVDF ultrasound microscope with biological applications. Acoustic Imaging 1988; 16: 511-20

6 Sherar MD, Foster FS. The design and fabrication of high frequency poly (vinylidene fluoride) transducers. Ultrasonic Imaging 1989; 11: 75-94.
(1)

7 Sherar MD, Starkoski BG, Taylor WB, Foster FS. A 100 MHz B-scan ultrasound backscatter microscope. Ultrasonic Imaging 1989; 11: 95-105.

8 Sherar MD, Noss MB, Foster FS. Ultrasound backscatter microscopy. Images the internal structure of living tumour spheroids. Nature 1987; 330: 493-5.

9 Reinstein DZ, Silverman RH, Trokel SL, Coleman DJ. Corneal pachymetric topography. Ophthalmology 1994; 101: 432-38.

10 Reinstein DZ, Silverman RH, Rondeau MJ, Coleman DJ. Epithelial and corneal thickness measurements by high-frequency ultrasound digital signal processing. Ophthalmology 1994; 101: 140-6

11 Azen SP, Burg KA, Smith RE, Maguen E. A comparison of three methods for the measurement of corneal thickness. Invest Ophthalmol Vis Sci 1979; 18: $535-8$.

12 Edmund C. Determination the corneal thickness profile by optical pachometry. Acta Ophthalmol 1987; 65: 147-52.

13 Gritz DC, McDonnell PJ. Comparison of a computer-assisted laser pachometer with two ultrasonic pachometers in normal corneas. Refract Corneal Surg 1990; 6: 9-14.

14 Reinstein DZ, Silverman RH, Trokel SL, Allemann N, Coleman DJ. Highfrequency ultrasound digital signal processing for biometry of the cornea in planning phototherapeutic keratectomy [Letter]. Arch Ophthalmol 1993; 111: 430-1.

15 Pavlin CJ, Easterbrook M, Hurwitz J, Harasiewicz K, Eng P, Foster FS. Ultrasound biomicroscopy in the assessment of anterior scleral disease. Am $¥$ Ophthalmol 1993; 116: 628-35.

16 Pavlin CJ, McWhae JA, McGowan HD, Foster SF. Ultrasound biomicroscopy of the anterior segment tumours. Ophthalmology 1992; 99: $1220-8$

17 Memmen JE, McLean IW. The long-term outcome of patients undergoing iridocyclectomy. Ophthalmology 1990; 97: 429-32.

18 Jakobiec FA, Silbert G. Are most iris 'melanomas' really nevi? A clinicopathological study of 189 lesions. Arch Ophthalmol 1981; 99: 2117-32.

19 Pavlin CJ, Harasiewicz K, Eng P, Foster FS. Ultrasound biomicroscopy of anterior segment structures in normal and glaucomatous eyes. $A m \mathcal{F}$ Ophthalmol 1992; 113: 381-9.

20 Pavlin CJ, Ritch R, Foster FS. Ultrasound biomicroscopy in plateau iris syndrome. Am F Ophthalmol 1992; 113: 390-5.

21 Panek WC, Christensen RE, Lee DA, Fazio DT, Fox LE, Scott TV. Biometric variables in patients with occludable anterior chamber angles. Am $₹$ Ophthalmol 1990; 110: 185-8.

22 Tello C, Chi T, Shepps G, Liebmann J, Ritch R. Ultrasound biomicroscopy in pseudophakic malignant glaucoma. Ophthalmology 1993; 100: 1330-4. 23 Chandler PA, Simmons RJ, Grant WM. Malignant glaucoma. Medical and surgical treatment. Am f Ophthalmol 1968; 66: 495-502.

24 Brown RH, Lynch MG, Tearse JE, Nunn RD. Neodymium-YAG vitreous surgery for phakic and pseudophakic malignant glaucoma. Arch Ophthalmol 1986; 104: 1464-6.

\section{Stem cells of the ocular surface: scientific principles and clinical applications}

The corneal epithelium exists in a state of dynamic equilibrium, with the superficial cells being constantly shed into the tear pool and renewed by proliferation and migration of the remaining cells. Migration occurs centripetally and circumferentially from the limbus and vertically from the basal layer forwards. Any organ that maintains its cell mass by a process of cell loss, renewal, and regeneration must possess a reservoir of 'stem cells'. Stem cells by definition have a high capacity for self renewal throughout the life of the organ(ism). ${ }^{1}$ Stem cells are long lived, have a long cell cycle time with a short S-phase duration, have an increased potential to error-free proliferation with poor differentiation, and demonstrate a capability to divide in an asymmetric manner. ${ }^{2-4}$ When a stem cell divides, one of the daughter cells remains as its parent and serves to replenish the stem cell pool, whereas the other daughter cell is destined to divide and differentiate with the acquisition of features that characterise the specific tissue. Such a cell is called a transient amplifying cell (TAC) and is less primitive than its parent stem cell. TACs differentiate into post mitotic cells (PMCs) and finally to terminally differentiated cells (TDCs). Both PMCs and TDCs are incapable of cell division. ${ }^{2}$ Such a hierarchy of cells exists at the corneoscleral limbus. The more primitive cells demonstrate certain intrinsic features such as the preferential expression of certain enzymes - for example, $\alpha$ enolase, show an abundance of epidermal growth factor receptors, co-express keratin 19 and vimentin, but do not express the differentiation marker, keratin K3/K12. Such cells are believed to represent corneal stem cells. ${ }^{35}$

What maintains the 'stemness' of a stem cell is not well understood. In addition to intrinsic factors mentioned above, extrinsic influences from the microenvironment also probably play a role. ${ }^{3}$ The microenvironment of the limbus differs from that of the central cornea by the presence and close proximity of blood vessels to the basal epithelial cells. ${ }^{6}$ The basement membrane of the limbus is modified to enhance epithelial cell adhesion and also possesses an abundance of type IV collagen which is absent from the central cornea. Conversely, a protein identified by 